\title{
Vaginal bleeding outcome in the third trimester of pregnancy
}

\author{
Hirani G. ${ }^{1 *}$, Hirani M. ${ }^{2}$ \\ DOI: https://doi.org/10.17511/joog.2020.i01.02 \\ 1* Gopal Hirani, Associate Professor, Department of Obstetrics and Gynaecology, Gujarat Adani Institute of Medical Science, Kutch, Gujarat, \\ India. \\ 2 Madhav Hirani, MS, Department of Obstetrics and Gynaecology, Hirani Hospital, Kutch, Gujarat, India.
}

Background and Aim: Maternal mortality form APH has reduced considerably in the last three decades due to improvements in obstetric care and blood transfusion services. Hence the purpose of the study was to study fetal and maternal outcomes in cases of third trimester vaginal bleeding. Materials and Methods: The study was conducted at the Institute of Medical Sciences. During this study period, 450 cases had an antepartum hemorrhage. All patients who came with a history of bleeding per vagina after 28 weeks of gestation were hospitalized. Cases with bleeding per vagina after 28 weeks of gestation were included in the study. Results: Out of total cases of the abrupt placenta, 12 percent cases were managed expectantly, 8 cases delivered within 6 days and 6 cases reached term and delivered vaginally and 89 (88 percent) cases were managed actively. Conclusion: At the level of a tertiary center, early recognition cause of APH, aggressive expectant management and termination of pregnancy after recording lung maturity, decrease in unnecessary $\mathrm{C} / \mathrm{S}$, good neonatal intensive care unit, active management of ideal cases will help in the improved outcome of maternal and perinatal outcome in antepartum hemorrhage.

Keywords: Antepartum Haemorrhage, Mortality, Vaginal bleeding

Corresponding Author

Gopal Hirani, Associate Professor, Department of Obstetrics and Gynaecology, Gujarat Adani Institute of Medical Science, Kutch, Gujarat, India.

Email: researchguide86@gmail.com
How to Cite this Article

Hirani G, Hirani M. Vaginal bleeding outcome in the third trimester of pregnancy. Obs Gyne Review J Obstet Gynecol. 2020;6(1):9-12.

Available From

https://obstetrics.medresearch.in/index.php/joog/art icle/view/97
To Browse

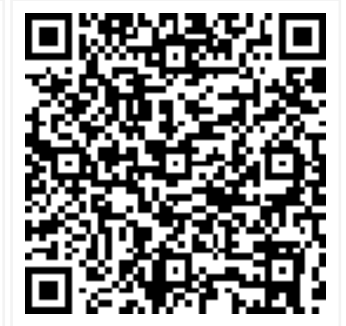

Manuscript Received 22-12-2019

Conflict of Interest No

Review Round 1
$02-01-2020$
Funding
Nil

Review Round 2 07-02-2020 Yes
Ethical Approval
Review Round 3

Plagiarism X-checker $13 \%$
Accepted 13-02-2020

(C) 2020 by Gopal Hirani, Madhav Hirani and Published by Siddharth Health Research and Social Welfare Society. This is an Open Access article licensed under a Creative Commons Attribution 4.0 International License https://creativecommons.org/licenses/by/4.0/ unported [CC BY 4.0]. 


\section{Introduction}

One out of 10 women will have vaginal bleeding during their 3rd trimester. At times, it may be a sign of a more serious problem. In the last few months of pregnancy, you should always report bleeding to your health care provider right away. When labor begins, the cervix starts to open up more or dilate. You may notice a small amount of blood mixed in with normal vaginal discharge, or mucus $[1,2]$.

Vaginal bleeding after mid-pregnancy is associated with maternal and fetal risks. Maternal morbidity may be caused by acute hemorrhage and operative delivery, and the fetus may be compromised by uteroplacental insufficiency and premature birth. Optimal management of late pregnancy bleeding depends on accurate identification of the cause and a timely intervention specific to its severity $[3,4]$.

Antepartum hemorrhage (A.P.H.) is one of the gravest obstetric emergencies, with dramatic suddenness a pregnant patient can become exsanguinated to the verge of death and her fetus may die. Unlike post-partum hemorrhage, which is always preceded by the adequate warning mechanism of labor, A.P.H. often occurs without warning $[4,5]$.

Antepartum hemorrhage is traditionally defined as any bleeding from the genital tract occurring after $28 \mathrm{wk}$ but before the onset of labor and delivery [6]. Earlier 28 weeks was a legal limit for fetal viability in many countries and it is now sensible to define it as bleeding occurring in 2nd half of pregnancy $\geq 20$ weeks.

Warning hemorrhage. Maternal mortality form APH has reduced considerably in the last three decades due to improvements in obstetric care and blood transfusion services. Hence the purpose of the study was to study fetal and maternal outcomes in cases of third trimester vaginal bleeding.

\section{Materials and Methods}

Study design, study setting, and study duration: The study was conducted in the Institute of Medical Sciences. During this study period, 450 cases had an antepartum hemorrhage. All patients who came with a history of bleeding per vagina after 28 weeks of gestation were hospitalized.

Ethical approval was taken from the institutional ethical committee and written informed consent was taken for the study participants.
Cases with bleeding per vagina after 28 weeks of gestation were included in the study, detailed history and examination of cases, blood investigations, ultrasonography was done and diagnosis of abruption placenta, placenta praevia and other cases who do not fit into these two categories grouped into unclassified and managed accordingly. If patients had come in an emergency without USG, a bedside emergency scan was done to confirm diagnosis and by per vaginal examination or retrospectively after the delivery.

\section{Inclusion Criteria}

1) Patient with third trimester bleeding which includes major causes abruption placenta, placenta Previa, unclassified type. 2) Patient from 28 weeks of gestation to delivery and discharge from the hospital.

\section{Exclusion criteria}

1) Patient with genital lesions who presents with bleeding is excluded. 2) patient less than 28 weeks of gestation Cases $>28$ weeks of gestation, with the diagnosis of abruption placenta, placenta praevia and unclassified variety were included in the study, local lesions of vagina and cervix were excluded from the study.

Sixty-four Cases with a history of bleeding per vagina after 28 weeks of gestation were admitted to the hospital. Diagnosis of placenta praevia, abruption placenta, and the unclassified type was made by clinical examination, USG and retrospective diagnosis after delivery by placental examination. Placenta praevia cases- with the live premature fetus, hemodynamically stable, with no or minimal bleeding and not in established labor were managed expectantly with tocolytics, antibiotics, steroids and bed rest.

Depending on the degree of anemia, the correction was done with either blood transfusion or parenteral iron therapy. This expectant management was continued until the term or maturity of fetus and later taken for elective $\mathrm{C} / \mathrm{S}$. Patient with a severe bout of bleeding, resuscitation did and emergency $\mathrm{C} / \mathrm{S}$ was done.

The patient is in established labor, with minimal bleed, good general condition and a minor degree of placenta previa, vaginal delivery was allowed. Abruptio placenta cases - patient not in labor and no maternal, fetal compromise expectant management done if it is preterm, until term with intense fetal and maternal monitoring. 
A patient presenting with grade 1 abruption placenta or depending more managed on the severity of bleeding, fetal maturity either by vaginal route or caesarean section. Patient with unclassified type- managed on the severity of bleeding, fetal maturity. The maternal and fetal outcome is noted.

\section{Results}

Out of the total 450 cases included in the study, 200 cases were diagnosed as abruption placenta, 64 cases were diagnosed as placenta praevia, and 186 cases were unclassified. Of these 450 cases, 320 were from rural areas and 32 were from urban areas. 261 were admitted as an emergency admission and 189 were booked, who had ANCs in our hospital or elsewhere.

In the current study maximum of 341 cases occurred between 21-30 years, 69 followed by in 16-20years, 40 cases occurred between >30years. Increasing age is an independent risk factor. The maximum number of cases was in multigravidae, the next number of cases were in Primigravidae and the least of them were Grandmultigravidae.

History of bleeding PV at the time of admission was seen in 450 cases. Of these 210 cases reported within 6hours. There was no history of bleeding PV in 80 cases (warning hemorrhage was not considered). Warning hemorrhage was seen in 50 cases of placenta praevia. Among those 240 percent,) admitted after 6hours, 60 patients were in shock all of whom were revived expect 2 cases. 16 cases had DIC.

Table-1: Incidence of antepartum hemorrhage in relation to age

\begin{tabular}{|l|l|l|}
\hline \multicolumn{1}{|c|}{ Sr. No. } & \multicolumn{1}{|c|}{ Age in years } & \multicolumn{1}{c|}{ Percentage } \\
\hline 1 & $16-20$ & 25 \\
\hline 2 & $21-30$ & 65 \\
\hline 3 & $>30$ & 10 \\
\hline Total & 100 \\
\hline
\end{tabular}

Table-2: Management of abruption placenta

\begin{tabular}{|l|l|l|}
\hline Sr. No. & \multicolumn{1}{|c|}{ Type of management } & \multicolumn{1}{c|}{ Percentage } \\
\hline 1 & Expectant & 12 \\
\hline 2 & Active & 88 \\
\hline Total & 100 \\
\hline
\end{tabular}

Table-3: Management of APH in unclassified hemorrhage

\begin{tabular}{|l|l|l|}
\hline \multicolumn{1}{|c|}{ Sr. No. } & \multicolumn{1}{|c|}{ Type of Management } & \multicolumn{1}{c|}{ Percentage } \\
\hline 1 & Expectant & 47 \\
\hline 2 & Active & 53 \\
\hline
\end{tabular}

Total 100

The fetal movements were present in 86.40 percent cases and the remaining 13.81 percent cases complained of loss of fetal movements. In abruption placenta loss of fetal movements was $56 \%$ and in placenta Previa $0.08 \%$. the perinatal loss was very much higher in abruption placenta, very less in placenta Previa. except in cases of vasaprevia, in severe bleeding as in major degree placenta praevia, premature fetus. Most of the patients with USG report were taken for emergency LSCS and if labor was established with diagnosed low lying placenta(4cases), vaginal delivery was allowed. cases, where placenta was not felt, was allowed for vaginal delivery. The remaining cases were taken for emergency $\mathrm{C} / \mathrm{S}$.

Out of total cases of the abrupt placenta, 12 percent cases were managed expectantly,8cases delivered within 6 days and 6 cases reached term and delivered vaginally and 89 (88 percent) cases were managed actively.

In the current study 53 percent were categorized into unclassified variety, 47 were managed on expectant line, as they were not in labor, with no active bleeding on admission, with a live preterm fetus without maternal or fetal distress. These patients were admitted to the hospital, started on antibiotics and tocolytics, steroids and with correction of anemia which was done with blood transfusion or iron preparation based on the severity of anemia.

\section{Discussion}

India being a developing country, with the majority of its population in rural areas, lack of basic medical care and transportation. With a high rate of illiteracy, early marriages and a high prevalence of anemia, it is important to counsel, diagnose, refer and manage a case of APH at a higher center [7]. Antepartum hemorrhage still ranks as one of the gravest obstetric emergencies. Even with the best obstetric care due to dramatic suddenness, a pregnant woman can become exsanguinated due to bleeding in the third trimester of pregnancy. It is one of the major causes of maternal and fetal mortality throughout the world, occurring in 3 to 4 percent of all pregnancies. All vaginal bleeding in the later month is alarming and want immediate evaluation. Second trimester bleeding though very common is seldom discussed due to low fetal salvage rate $[8,9]$. 
The risk of placenta previa is highest in the pregnancy immediately following cesarean section. Failure of appropriate lower segment devolvement, because of scar tissue could be the cause and raw area favorable for implantation. A clinical study of 112 cases at Pondicherry in 2001 on perinatal mortality and morbidity more in the third trimester bleeding cases revealed that incidence of IUD in cases of Abruption was much higher than in Placenta Praevia. A 10 year study conducted including 306 cases on risk factors and pregnancy outcome in different types of placenta praevia reported incidence of placenta praevia $0.73 \%$ and concluded major degree associated higher morbidity than low lying type [10].

Out of 450 cases, 88 percent were from rural areas. Most of these cases were unbooked and were admitted as emergency admissions. Both maternal morbidity and neonatal mortality were observed to be more in these cases. James Scot studies concluded that higher maternal and fetal morbidity and mortality in unbooked cases Majority (26 -81.25 percent) of cases were managed actively as they were not fit for expectant management. 4 (12.5 percent) patients were in hypovolaemic shock, 11 cases (34.37 percent) were in established labor, 26 (81.25 percent) cases had profuse bleeding, 4 (12.5 percent) had IUD. 23 underwent emergency cesarean section and 3 cases delivered through vagina who had type 1 placenta Previa, 8 babies died of prematurity, respiratory distress. In the current study 6 cases (18.75 percent) were managed on expectant line, as they were not in labor, with no active bleeding on admission, with a live preterm fetus without maternal or fetal distress. These patients were admitted to the hospital, started on antibiotics and tocolytics with correction of anemia which was done with blood transfusion or iron preparation based on the severity of anemia. The majority (88-92.70 percent) of cases were managed actively, expectant management is done in a very small number of cases like it as the very little role in abruption placenta. 24 cases underwent emergency LSCS and 64 delivered vaginally. 42 babies died including antepartum, intrapartum, postpartum period. The limitation of this study is the determination of the intensity, amount and frequency of bleeding that appears to be an effective factor at the end of pregnancy. It is also suggested that the relation of third trimester vaginal bleeding to the sex of newborns in current and previous pregnancies as well as body mass index to be evaluated in the next studies.

\section{Conclusion}

At the level of a tertiary center, early recognition cause of $\mathrm{APH}$, aggressive expectant management and termination of pregnancy after recording lung maturity, decrease in unnecessary C/S, good neonatal intensive care unit, active management of ideal cases will help in the improved outcome of maternal and perinatal outcome in antepartum hemorrhage.

\section{Addition of the study to existing knowledge}

Awareness through antenatal classes, better socioeconomic status, efficient referrals system, good neonatal intensive care facilities is obviously required for the fetal perinatal and maternal outcome in developing countries.

\section{Author's contributions}

Dr. Gopal Hirani formulated the aims and objectives with study design and helped in data collection from the medical record department.

Dr. Madhav Hirani contributed to the preparation of the manuscript and data analysis.

\section{Reference}

01. Pratt DS, Kaplan MM. Evaluation of abnormal liver-enzyme results in asymptomatic patients. New Eng J Med. 2000;342(17)1266-1271.

doi: [10.1056/nejm200004273421707] [Crossref]

02. Rayburn WF. Prostaglandin E2 gel for cervical ripening and induction of labor- a critical analysis. Am J Obstet Gynecol. $1989 ; 160(3) 529-534$.

doi: $10.1016 / \mathrm{s} 0002-9378(89) 80020-10$ [Crossref]

03. Chilaka VN, Konje JC, Clarke S, Taylor DJ. Practice observed- is speculum examination on admission a necessary procedure in the management of all cases of antepartum haemorrhage?. J Obstet Gynaecol. 2000;20 (4)396-8. doi: [10.1080/01443610050112057] [Crossref]

04. Sakornbut E, Leeman L, Fontaine P. Late pregnancy bleeding. Am Fam Physician. 2007;75(8)1199-1206.

[Crossref:Crossref] 
05. Dhanalakshmi K. Outcome of pregnancy in third trimester vaginal bleeding. 2011.

[Crossref]

06. Jacobsson B, Hagberg G, Hagberg B, Ladfors L, Niklasson $A$, Hagberg $H$. Cerebral palsy in preterm infants- a population?based case? control study of antenatal and intrapartal risk factors. Acta Paediat. 2002;91(8)946-951.

doi: [10.1111/j.1651-2227.2002.tb02860.x] [Crossref]

07. Tinker, Anne G. Improving women's health in Pakistan (English). Health, nutrition, and population series. Washington, DC 1998, The World Bank. Available at

[Article] [Crossref]
08. Siddiqui F, Kean L. Intrauterine fetal death. Obstetrics Gynaecology and Reproductive Medicine. 2009;19(1)1-6.

doi: [10.1016/j.ogrm.2008.09.007] [Crossref]

09. Tuzovic L. Complete versus incomplete placenta previa and obstetric outcome. Int J Gynecol Obstet. 2006, 93(2)110-117.

doi: [10.1016/j.ijgo.2006.02.006] [Crossref]

10. Weiss JL, Malone FD, Emig D, Ball RH, Nyberg DA, Comstock $\mathrm{CH}$, et al. Obesity, obstetric complications and cesarean delivery rate a population-based screening study. Am J Obstet Gynecol. 2004;190(4)1091-1097.

doi: [10.1016/j.ajog.2003.09.058] [Crossref] 